\title{
As práticas do dizer e os processos de subjetivação
}

\author{
Silvia Tedesco \\ Universidade Federal Fluminense
}

\begin{abstract}
RESUMO
Seguindo ponto de vista transdisciplinar na clínica, o trabalho analisa a aliança entre os estudos da subjetividade e algumas propostas de Foucault e de Deleuze. A proposta é redefinir a clínica a partir da crítica à concepção de subjetividade como substância, naturalizada por leis universais estritamente psíquicas, responsáveis por sua regularidade e contornos conceituais bem delimitados e imutáveis. A relação entre subjetividade e práticas discursivas é explorada como processo de produção recíproca, onde modos de dizer e modos de existir emergem dos jogos de forças. Duas modalidades de movimento das forças são sublinhadas, deixando ver os dois pólos do processo de subjetivação: produções subjetivas homogeneizantes e invenção de novos modos de funcionamento. A tarefa clínica, neste contexto, se cumpriria no zelo pelo duplo movimento, pelo qual a subjetividade preservaria seu caráter processual, distante de uma constituição substantiva.
\end{abstract}

Palavras-chave: subjetividade; clínica; literatura

\begin{abstract}
The discursive practices and subjectivity

Assuming a transdisciplinary point of view in the clinical work, this paper investigates the alliance bet ween the studies of subjectivity and the thought of Foucault and Deleuze. Our purpose is to redefine clinical practice in accordance with their critique of the conception of subjectivity as a substance, naturalized by strictly psychological universal laws, responsible for their regularity and well established and unchangeable conceptual contours. The relationship between subjectivity and discursive practices is explored as a process of mutual production, in which speech modalities and modalities of existence emerge from the interplay of forces. Two modalities of the forces in movement are emphasized, so that the two poles of the process of subjectivation can be seen: subjective productions that lead to homogenization and the invention of new modes of existence. In such context, the clinical task would be carried out by carefully maintaining the double movement, by which subjectivity could preserve its processing nature as opposed to a substantial constitution.
\end{abstract}

Keywords: Subjetivity; clinic; literature

A obra de Foucault força a clínica a repensar a subjetividade, convocação presente em sua crítica dirigida à crença na fixidez do mundo, à afirmação da universalidade de seus objetos. Sobre isto Foucault (1987) nos adverte:

O objeto não espera nos limbos a ordem que vai liberálo e permitir-lhe que se encarne em uma visível e loquaz objetividade; ele não pré-existe a si mesmo, retido por algum obstáculo aos primeiros contornos da luz, mas existe sob as condições positivas de um feixe complexo de relações (p. 51).

No caso da clínica, a crítica recai sobre a concepção de subjetividade tratada como substância, entidade dada desde sempre, naturalizada por leis universais estritamente psíquicas, que a regrariam e lhe assegurariam contornos conceituais bem delimitados e imutá- veis. A partir do ponto de vista transdisciplinar, este trabalho afirma uma possível aliança entre os estudos da subjetividade e o pensamento foucaultiano.

Somos também advertidos da perigosa armadilha de orientarmos a investigação de nosso objeto de estudo pela busca da Ursprung, no estabelecimento de origem nobre, de relações de continuidade, de identidades. No lugar, Foucault (1979), inspirado em Nietzsche, propõe a pesquisa da Herkunft, da proveniência que "agita o que se percebia imóvel, fragmenta o que se pensava unido, mostra a heterogeneidade do que se imaginava em conformidade consigo mesmo" (p. 21)

São as relações de poder, ou seja, relações de produção política que passam a nos interessar. Afetada por esta indicação, a clínica amplia seus contornos. Sublinhamos o efeito principal desta decisão. Despre- 
za-se o caráter eterno e estritamente psíquico de seu objeto. Mais além e mais aquém da forma delimitada, que podemos denominar sujeito, o trabalho clínico dirige-se a um processo mais amplo o qual denominamos processo de subjetivação. Nele, a subjetividade se exerce como processualidade, realizada num plano histórico-político a partir do qual a forma sujeito emerge como efeito. A clínica lida com formas ou modalidades subjetivas móveis: contingentes e provisórias.

Portanto, falar de subjetividade é falar de uma maquínica, de um processo de produção dirigido à geração de modos de existências, ou seja, modos de agir, de sentir, de dizer o mundo. É analisar um processo de produção que tem a si mesmo, o sujeito, como produto. Precisamos entender a subjetividade ao mesmo tempo como processo e produto. Como produto reencontramos a noção de sujeito, objeto de estudo das ciências humanas, figura cujos limites são delineados por regularidades garantidas por princípios gerais de funcionamento. No entanto, lembrados por Scherér (1998) concordamos que "seria um erro não reconhecer que esta forma regular corresponde apenas a um instante único da subjetividade, um momento de um processo maior, uma fase de uma atividade contínua de produção de si" (p. 64).

$\mathrm{E}$, então, mais do que o efeito-sujeito ou produto-sujeito, a subjetividade inclui também uma dimensão de processo. Falar da subjetividade como processo de produção implica em falar do plano onde este processo de produção, este processo de construção do si, ocorre. Como consequência, precisamos considerar o caráter político, as relações de poder que compõem este plano, as relações de forças implicadas no processo de produção. Afirmamos ser o plano das forças, produtoras da forma subjetiva, uma dimensão própria à subjetividade.

A clínica, portanto, não remete os impasses do sujeito a uma realidade essencialmente psíquica, circunscrita a conflitos intimistas, ou mesmo a estruturas subjetivas universais. Ela traz a cena o plano de forças, no qual lutas, impasses constantes, exprimem certa modalidade de funcionamento. Para além do sujeito constituído, produzido, existe a subjetividade, modo como denominamos seu plano de produção. Este plano torna-se o real objeto da clínica.

Referir-se à subjetividade é referir-se às relações, à rede de conexões que a constituem. Vale como esclarecimento que nesta rede, o sujeito não vigora como termo preexistente que, então, de acordo com características próprias, estabeleceria elos de vida com o meio circundante. Não fazemos referência a um sujeito destacado dos objetos do mundo, nem a uma realidade psíquica que estabeleça relações de representação com uma pretensa realidade externa, dada desde sempre e dela separada. Não há dicotomia sujeito-objeto ou sujeito-mundo. O que temos é a subjetividade como um plano de forças, onde tanto o sujeito quanto o mundo são já efeitos. A subjetividade não participa da rede, ela constitui a própria rede.

Ao transportar nossa análise para o plano das forças lembramos com Foucault, em sua aliança com Nietzsche, que as forças só podem ser apreendidas em seu exercício. Toda força está numa relação essencial com outra força. Neste sentido, ao falarmos das forças de produção da subjetividade estaremos tratando essencialmente de relações de produzir e ser produzido.

Dito isto, para melhor conduzir esta exposição escolho um outro termo, um segundo termo, um outro conjunto de vetores para sublinhar o caráter relacional da subjetividade. Escolha recai sobre o processo da linguagem. Escolha em nada casual na medida em que a sociedade contemporânea faz uso especial da linguagem. O poder disciplinar, exercido no confinamento das instituições, substitui-se pelo exercício do controle aberto, que circula pelas distâncias, pelos espaços vazios. No entanto, somos advertidos que estes espaços são ilusoriamente vazios, porque recobertos pela ampla rede da comunicação. Conectados na rede, somos "acessados", a qualquer instante, em qualquer lugar. A linguagem tornou-se essencial à sociedade de controle (Deleuze, 1992).

Ao tomar a subjetividade nas relações com a linguagem, vou acentuar este entre dois, pois não são os termos linguagem e subjetividade, tomados cada um isoladamente, que nos interessam, mas o elo, isto, é a relação de forças de produção que faz emergir os dois termos. Nesta relação de produção temos esclarecido o caráter pragmático/político do elo, que nos permite equivocar as direções mais tradicionais da análise do vínculo entre linguagem e subjetividade, seja na visão da psicologia, seja na da psicanálise. Não tomamos a enunciação como a manifestação de um sujeito dado, ou seja, o dizer não resulta de um conjunto de faculdades, de processos fixos, regulados por princípios gerais, como por exemplo, nos fala a psicologia. $\mathrm{O}$ "eu falo", sujeito da enunciação e origem da linguagem, perde, para nós, seu lugar central. Como diz Foucault (1987), a verdade ou a causa das enunciações não deve ser procurada na unidade de um sujeito. O sujeito não é agente nem ponto de partida do dizer.

$\mathrm{E}$, se não optamos por considerar o discursivo como expressão de uma consciência anterior à palavra, muito menos ainda falaremos da linguagem como fundamento do sujeito, isto é, de um sujeito do 
inconsciente, estruturado como uma linguagem, um sistema simbólico no qual o sujeito estaria imerso. Se negamos à subjetividade a função de fonte ou origem da linguagem, do mesmo jeito rejeitamos a tese psicanalítica do sujeito constituído exclusivamente pela e na linguagem. Não apostamos na simples inversão da direção imposta ao vetor de determinação. Propomos, bem mais que isto, propomos a transversalização destas coordenadas tradicionais de determinação. No lugar da dicotomia entre determinante/determinado, marcada por relações de hierarquia ou predominância, prevemos a reciprocidade entre os termos, reciprocidade catalisadora de engendramentos mútuos. Cada um dos termos é, a um só tempo, agente de produção e também produto.

Em seguida, fazemos notar que se orientar pela pragmática foucaultiana implica em não referir-se à linguagem como instrumento/processo de representação seja da verdade do mundo, seja dos fatos ordinários do cotidiano dos sujeitos. A linguagem é uma prática, uma prática discursiva que interfere, transforma a realidade. A velha dicotomia fundada na afirmação de um abismo intransponível que aparta linguagem e vida fica para traz. De um lado afirmava-se a vida, como processo em perpétua transformação, nele comparecendo variações, devires, de outro o universo dos representantes, mundo da linguagem em sua organização imóvel e função organizadora das irregularidades factuais. Sob este ponto de vista, linguagem seria puro marcador de poder ordenador, emprestando continuidade homogênea à enlouquecida variação dos fatos.

Inspirados por Foucault a seguir direção diversa, elimina-se o isolamento pragmático entre linguagem e realidade. De modo que a realidade produzida pelos discursos é de natureza lingüística, mas não menos real do que a realidade extradiscursiva. Pertencente ao plano das práticas, a linguagem é também exercício de realizações empíricas. Constitui objetos, cria situações novas. Enfim, a produção do mundo tem agora afinidade especial com a linguagem.

Ao incluir a linguagem no plano das práticas é preciso estar atento à preservação dos limites do universo discursivo. Isto porque à primeira vista, afirmar a incursão direta dos ditos entre os fatos em geral, poderia implicar no risco de defini-lo numa relação de continuidade com toda ação ou gesto, diluindo-o entre os fatos. Ao contrário, o dizer torna-se prática, mas não uma prática qualquer, ou seja, ela mantém-se distinta de outras práticas, guarda especificidade. Porém não guarda seu poder hegemônico, sua prevalência como força de determinação, de ordenação, $\mathrm{O}$ plano de produção a que fazemos referência é um plano heterogêneo, onde práticas discursivas e não discursivas agem umas sobre as outras, num movimento de mútua produção. Sem o não discursivo, o discursivo não se realiza. Vejamos.

Algumas teses desenvolvidas principalmente na “Arqueologia do saber" Foucault (1987) e relidas por Deleuze (1988) nos autorizam a pensar o dizer a partir da noção de formação histórica e, deste modo, envolvem a linguagem no processo de produção de mundo. Segundo Foucault, a empiricidade sofre a repartição em duas dimensões, cada uma com a mesma força produtiva. As práticas discursivas e as não discursivas recobrem a realidade e constituem-se em duas modalidades de produção. Na primeira se localizam as práticas centradas no uso de signos, toda e qualquer atividade envolvida com a expressão. Tal é a realidade constante nas leis, nos códigos, nos enunciados estabelecidos pelas convenções institucionalizadas ou informais, presentes em qualquer esfera do cotidiano. É também o mundo posto pelas teorias, pelas hipóteses explicativas, que percorrem todos os limiares de cientificidade de que fala $\mathrm{M}$. Foucault, desde a formalização às puras positividades, incluindo-se aí, também, qualquer opinião, a mais corriqueira, ou um simples traçado de letras sobre uma folha de papel. Qualquer conjunto de signos ou sinais é um dizer que, ao pretender referir-se ao mundo, na verdade, o está produzindo (Foucault, 1987). Na segunda encontramos as práticas empíricas afetando diretamente corpos e coisas. É o plano das ações mudas, das visibilidades. Estas agem realizando as repartições, distribuições dos espaços que resultam em diferentes modalidades de confinamentos, através das quais doam realidade a distintas qualificações para os corpos. De um lado, os atos, realizações vinculadas às enunciações, de outro as ações mudas.

No lugar do privilégio oferecido a um dos planos no poder de organização formal surgem duas formas autônomas. Os dois planos existem como dois aspectos de um mesmo plano mais amplo, o das empiricidades, e possuem, cada um, seu modo próprio de organização. A autonomia dos dois planos os mantém-se distintos, porém, não mais isolados. Não escapam a relações de reciprocidade. A realidade empírica definida como efeito de práticas é, na verdade, uma função e explica-se pela relação de pressuposição mútua, estabelecida como resultante de dois funtivos: o discursivo e o não discursivo ou dizibilidade e visibilidade (Deleuze, 1988; Foucault, 1987).

A repartição realizada acima ganha maior clareza quando os dois funtivos revelam-se como formações, como processos histórico-políticos. Trata-se da grande rede discursiva de que falávamos no início do traba- 
lho, agora, esclarecida também através de seus componentes não discursivos. Da gênese empírica das visibilidades criam-se modos de ver e fazer ver, já da produção das dizibilidades surgem maneiras específicas de falar e fazer falar. É no conjunto de falas e olhares que o objeto se constitui. Porém, qual seria a modalidade de elos produzidos por esta grande rede empírica produtora de realidade?

Seguir a tradição pragmática nos conduz a conceber o duplo funcionamento do elo em questão. E com isso o sentido de produção abala-se. Ao falar de produção consideramos simultaneamente dois sentidos que o termo carrega. Entendida como pura repetição, o processo de produção tende a imprimir no produto sempre uma mesma natureza, ou melhor, o efeito não diverge da direção imposta pela configuração geral do processo. Tal como numa fábrica, esta modalidade de produção prima pela realização de cópias bem feitas, ou seja, orienta-se pela qualidade da produção, ou melhor, pela qualidade da reprodução. Vigora aí o cuidado com produto, cuidado com sua fidelidade ao modelo geral, fidelidade a uma matriz que deve ser reproduzida. São as produções serializantes, homogeneizantes.

Porém, existem momentos em que segmentos do processo de produção, no lugar de reproduzir reiteradamente um mesmo efeito, segue direções inusitadas, instala-se como uma estranha modalidade de produção, na qual o processo volta-se sobre si mesmo. A força em jogo acumula dupla função. Ela se exerce, simultaneamente como receptividade e espontaneidade. Afeta a si própria, propõe ao processo direções inesperadas, impondo diferenciação às suas próprias linhas de produção. Neste caso, é o próprio processo que é fabricado. O processo ocupa o lugar de produto. Ou melhor, processo e produto são, agora, indiscerníveis. Trata-se de um produto-processo, em que a engrenagem maquínica da vida, ela mesma, passa por transformações, garantindo o surgimento de novas regras de funcionamento para a máquina-subjetividade. Ou seja, em seu duplo funcionamento, o elo entre linguagem e subjetividade ora reproduz, ora inventa os dois termos do par.

A compreensão do primeiro movimento de produção, produção de produtos nos conduz às teses foucaultianas sobre a gênese histórico-política da realidade. Esta gênese, resultado de formações políticas, atravessa todo o plano das empiricidades: são as práticas de discursivas e não-discursivas. O olhar e o dizer a realidade são práticas ao mesmo tempo produzidas e produtoras daquilo que tomamos como realidade.
(Deleuze, 1988; Deleuze \& Guattari, 1980; Foucault, 1987).

No caso da linguagem, é da potência dos ditos apontarem numa direção comum, a do objeto a ser produzido. Certa convergência entre os discursos é observada, mas nada que se aproxime da identidade. Não é exatamente o mesmo objeto descrito em cada um dos discursos. Não há homogeneidade na maneira de descrevê-lo. A realidade do objeto abriga a dispersão entre as falas, compõe também com suas divergências. Longe de se organizarem numa categoria clara, num conceito com contornos precisos, tal como o pensamento da representação clássica ${ }^{1}$ almejava, os conjuntos de falas estabelecem entre si jogos, jogos de poder cuja resultante faz emergir o objeto produzido. Enfim, o encadeamento de discursos produz as condições discursivas, ou seja, impõe o enquadre da conversação, determinando o que pode ser dito. A linguagem institui novas realidades a serem tratadas, novos objetos empíricos.

Também no plano das visibilidades, a ressonância entre práticas de natureza não discursiva cria formas particularizadas de visibilidade, diferentes maneiras de ver. Criam condições de visibilidade, o pedestal que sustenta e ao mesmo tempo ressalta, dá a ver os objetos. São estratégias que especificam, doam contornos às coisas e aos corpos. A forma de visibilidade prisão, por exemplo, faz ver presos, a da escola, alunos. A arquitetura específica destes espaços, com os seus regimes de vida forjados pela função dos horários e das atividades - o que fazer, como fazer, quando, onde - constróem os objetos do plano das visibilidades (Foucault, 1987). Estas formações históricas são formas de luminosidade, tal como descritas pelos impressionistas, "para quem a luz era uma forma, criava suas próprias formas e seu próprio movimento" (Deleuze, 1988, p. 60).

Embora autônomos, os dois planos apenas existem na reciprocidade de relações. Cada um ostenta sua forma própria, com um modo particular de produção de realidade. Porém, atravessam-se mutuamente. Há sempre algo visto compondo os pressupostos implícitos do dito, assim como os ditos também se incluem quase silenciosamente na produção do ver. Ou seja, nos interstícios do visível inserem-se palavras, ao mesmo tempo em que as condições do ver interferem na produção dos ditos, infiltram-se nas práticas lingüísticas. As divergências entre as produções dos dois planos não comprometem o entrecruzamento entre eles, ao contrário servem à montagem conjunta. De modo que o valor pragmático dos signos é decidido no jogo realizado entre os dois funtivos do empírico. 
Se os objetos visíveis e enunciáveis são gerados no entrecruzamento dos discursos e dos dispositivos de visibilidade, disponíveis numa dada época -, devemos entender forma a partir de seu processo de produção histórica. A forma é entendida como construção empírica. A forma é, na verdade, uma formação. E é exatamente neste sentido que falávamos antes de sujeito ou forma sujeito. Sem preexistência, ela é, ao mesmo tempo, produzida e temporária.

Entre as realidades produzidas no plano de produção registramos a forma subjetiva, a subjetividadeproduto. Um fato subjetivo é um efeito do encadeamento de práticas diversas, um entrecruzamento de determinações enunciativas e não enunciativas. A produção de realidades processa-se na pluralidade de discursos, advindos dos diversos saberes e práticas. No conjunto de falas a forma-sujeito constitui-se como objeto discursivo. A força de intervenção sobre $\mathrm{o}$ mundo adere-se à palavra $\mathrm{e}$, uma vez pronunciada, não há como desfazê-lo. Ela deixa sua marca, o selo indiscutível e irredimível de um comando. A linguagem, na sua atividade de descrição, engendra, ela mesma, o próprio objeto descrito. Ela atua destacando, constantemente, temas subjetivos que, tomados nas cadeias de discursos, ganham peso de realidade atemporal.

Um conjunto de discursos faz os corpos comportarem-se como se eles se acreditassem, se vissem como sujeito, dotado de uma natureza geral regida por princípios constantes. A forma-sujeito surge então em sua homogeneidade forjada, decidida nos pressupostos implícitos do dito. O processo em seu todo tem seu início num conjunto de dizeres heterogêneos, porém alinhados e redundando no isolamento do enunciado e na produção de um si mesmo como pretenso agente da enunciação.

Mas, como afirmamos antes, existe no elo com a linguagem uma segunda modalidade de produção. A produção de si mesmo, produção do próprio processo. São momentos em que a produção bifurca, seus efeitos desviam-se da rota esperada e, na estranheza desta ruptura, geram modos de subjetivação ainda desconhecidos.

Este movimento alimenta-se da experiência que Foucault (1994) escolheu nomear como experiência do fora, "experiência flutuante, estrangeira, como exterior a nossa interioridade" (p. 522). Esta dimensão, ao mesmo tempo distante da formalização da linguagem e do sujeito, liga-se à ruptura dos estados, libera-os da identidade, para colocá-los em variação. Pensemos no fora como poros da realidade pretensamente contínua e efeito do plano de produção, poros, com alto grau de indeterminação, sempre prestes a romper a ordenação dos sistemas sem, no entanto, abandonar a superfície a que pertencem. Uma vez afetado pelo fora, o processo de produção da subjetividade escapa à serialização para gerar, como vimos, novas normas de funcionamento maquínico e, com ele, produtos existenciais até então, desconhecidos.

No domínio da linguagem - na arte literária ou em modalidades linguajeiras do cotidiano que escapam a regularidade do idioma padrão - vemos certas construções lingüísticas definirem-se por sua condição paradoxal ${ }^{2}$. Revelam-se como fenômenos mistos de linguagem, carregados de variação irredutível à qualquer forma unificada. São construções marcadas por diversidade interna, onde componentes lingüísticos se agridem, construindo sentidos sempre divergentes, resistentes à unificação.

No contato com a heterogeneidade da linguagem a unidade fictícia do eu fragmenta-se, abandona as modalidades subjetivas repetidoras, serializantes, para ativar seu caráter de deriva, engajada na criação de novos sentidos, na construção de novos modos de dizer e também de experimentar a vida. Ou seja, como efeito do conjunto paradoxal de dizeres é dado à subjetividade viver variadas modalidades de pensar, de sentir, de viver no mundo. O sentido bifurcante dos signos faz proliferar modos de subjetivação singularizantes (Rolnik, 1996).

É também na relação com a linguagem que a subjetividade ganha velocidade de variação, que os contornos da figura sujeito são desfeitos e geram-se focos mutantes de subjetivação. Os dois processos, significância e subjetivação, mantêm-se solidários, fortemente articulados. Desse modo, a desestabilização da ordem da linguagem pode servir à dissolução das figuras subjetivas. Nesta outra modalidade de realização do processo, a relação entre os componentes não é da ordem da repetição. Um intervalo qualitativo (distância) separa esses componentes, existentes como disparidades. As relações não produzem unificação. Elas lidam com zonas de indiscernibilidade, nas quais o estabelecimento de limites precisos está excluído (Deleuze \& Guattari, 1980). Tal composição doa ao processo características automodelizantes, esclarecendo o caráter autônomo do processo.

As propriedades automodelizantes foram esclarecidas por Varela (1989), na noção de autonomia de um sistema. Um sistema é autônomo quando é capaz de gerar suas próprias regras de funcionamento no lugar de ser controlado por regras constantes. Isto nos permite dizer que o processo de subjetivação singularizante instaura na subjetividade novos modos de fun- 
cionamento, regidos por princípios sempre inventados e transitórios.

Surgidas dos limites da forma-sujeito, da sua sensibilidade ao diverso, o processo de subjetivação bifurcante distancia-se das determinações subjetivas estabilizadas para criar novas experiências de mundo, dispositivos heterogêneos, fugidios, atitudes não repertoriáveis e sempre desconcertantes para a figura subjetiva. Vemos claramente que aqui a subjetivação tem pouco a ver com sujeito, produto dos jogos de poder emergentes na rede formada pelo discursivo e pelo não discursivo. Trata-se da invenção de novas possibilidades de vida, da produção do si autônomo. O sujeito, figura definível por coordenadas pessoais, é levado a abandonar os complexos intrapsíquicos, as tentativas de unificação, em nome da invenção de outras normas de regulação do si. Enfim, a subjetividade é pensada como maquínica de subjetivação híbrida, funcionando no entrelaçamento das duas faces distintas do movimento. De um lado, o sujeito, individuação pessoal e regular, de outro o a-subjetivo, plural e impessoal. No limite entre as duas tendências definimos a subjetividade como processo incansável de produção, cuja resultante principal é a forma sujeito com seus contornos facultativos e temporários.

A tarefa clínica, neste contexto, se cumpriria no zelo pelo duplo movimento, pelo qual reconhecemos o caráter cambiante da subjetividade. Quando determinada configuração da rede discursiva/não discursiva, no seu movimento convergente de produção de realidade, obstaculiza o nomadismo da subjetividade, caberia a intervenção clínica reenviar o sujeito ao seu plano de produção e deste modo incitar a maquínica a retomar seu movimento.

Se "a escolha ético-política que temos que fazer a cada dia é determinar qual é o perigo principal"
(Foucault, 1984, p. 44), e se, neste caso, a naturalização da realidade psíquica, cômodo referencial homogeneizante para as iniciativas de normalização, é dita ocupar este lugar, a clínica comparece na interrogação da paralisia do processo, na descrença nos referenciais absolutos de julgamento da subjetividade para recolocá-la a caminho de outras formas ainda impensáveis, para fazê-la afirmar-se como real inventora de si.

\section{REFERÊNCIAS}

Deleuze, G. (1992). Conversações. Rio de Janeiro: Ed. 34.

Deleuze G. (1988). Foucault. São Paulo: Brasiliense.

Deleuze, G. \& Guattari, F. (1980). Mille Plateaux. Paris: Minuit.

Foucault, M. (1994). La pensée du dehors. Em M. Foucault, Dits et écrits: Vol. 1 (pp. 518-539). Paris: Gallimard.

Foucault, M. (1979). Microfísica do poder. Rio de Janeiro: Graal.

Foucault, M. (1987). A arqueologia do saber. Rio de Janeiro: Forense.

Foucault, M. (1984). Sobre a genealogia da ética. Em C. H. Escobar (Org.), O dossier - Últimas entrevistas (pp. 7-40). Rio de Janeiro: Taurus.

Rolnik, S. (1996). Esquizoanálise e antropofagia. Cadernos de Subjetividade, 4, 83-94.

Schèrer, R. (1998). Subjetivités hors sujet. Em R. Schèrer, Regards sur Deleuze (pp. 99-106). Paris: Kimé.

Tedesco, S. H. (1999). Estilo-subjetividade: considerações a partir do estudo da linguagem, Tese de doutorado não publicada, Programa de Pós-graduação em Psicologia Clínica, PUC-SP.

Tedesco, S. H. (2003). Las políticas del decir en la produción de la violencia. Santiago, 101, 01-106.

Varela, F. (1989). Autonomie et connaissance. Paris: Seuil.

Recebido: $31 / 05 / 2006$ Revisado: 07/08/2006 Aceito: $25 / 11 / 2006$

Notas:

1 O conceito de representação a que fazemos referência foi tratado em trabalho anterior (Tedesco, 1999).

2 Sobre modalidades dispersantes da linguagem cf. Tedesco $(1999,2003)$.

\section{Sobre a autora:}

Silvia Tedesco: Doutora em Psicologia pela Pontifícia Universidade Católica da São Paulo; professora adjunta da graduação e do Programa de Pós-graduação em Psicologia do Departamento de Psicologia - UFF

Endereço para correspondência: Silvia Tedesco - Universidade Federal Fluminense - Campus Gragoatá, prédio "O" - sala 214

-24210-350Niterói - RJ - Endereço eletrônico: stedesco@ novanet.com.br. 